\section{The misuse of mathematics in economics*}

NeITHER the utility function $U=U(x)$ nor the production function $O=O(z)$ are functions in the mathematical meaning of that term. That is, no rule is provided by which, given $U(x)$, the value of $U$ can actually be computed, and similarly for $O$ and $O(z)$. We may be told that $U(x)$ and $O(z)$ are monotonically increasing and concave functions, but nothing more beyond such general statements. In consequence, there is not enough information to obtain an actual solution .... By the very statement (or, rather, incomplete statement) of the problem, it is impossible to solve it! . . . This peculiar way of half-posing problems can be traced back to quite early times, but it was given its main impetus by Paul Samuelson in his very influential Foundations of Economic Analysis ...

Why are problems of pure economic theory stated in such a peculiar, incomplete fashion? The reason is not far to seek. The utility function $U(x)$ is not given explicity

\section{demand itself.}

The growth of output per worker as one form of technical progress - to the extent it leads to a corresponding rise in real income - can be shown to determine, along with the growth of population, the longterm growth of final demand, while the variation in investment and other forms of discretionary expenditures can be shown to determine the cyclical movements of the economy around that trend line $e^{4,5}$. This explanation for what happens at the industry and aggregate level, insofar as quantities supplied and relative prices are concerned, can then be supplemented by various 'behavioural' (as distinct from 'rationalist') models of what happens at the individual firm and household level. In this way, a complete and comprehensive alternative to the prevailing theories in economics can be developed-one that appears better able to meet the empirical tests necessary to establish economics as a scientific discipline $e^{6,7}$.

\section{Beliefs}

The existence of this alternative nonetheless continues to be ignored by most economists, along with the evidence on which it is based, simply because it is not consistent with the four theoretical constructs that constitute the core of ecomonic theory. Thus the prevailing theory in economics is based on an a priori set of beliefs rather than on any empirical evidence. In this respect, it is more akin to a religious credo than to any scientific body of knowledge. However, it is not just in refusing to accept the need for empirical because it cannot be given. It is an artificial construct of the theorist's mind and does not correspond to anything in the real world .... Exactly the same is true of the production function $O(z)$. It is now more than a quarter of a century since Joan Robinson' demonstrated that the quantity of capital, [one of the $z$ 's] of that theory, is impossible to define consistently. Nonetheless, this very quantity still appears, with monotonous regularity, . . . in . . . innumerable papers on pure economic theory . . . All of this is not the application of mathematics to the economic problems of the real world. Rather, it is the application of highly precise and elaborate mathematics to an entirely imaginary and fanciful economic cloud cuckoo land.

* An extract taken from J. Blatt, pp. 169-171 in ref. 1 . The nomenclature of the mathematical functions is slightly changed to correspond with the convention used elsewhere in this article.

proof of its key propositions that the prevailing practice in economics runs counter to scientific norms. The violation of scientific norms also involves the following two fallacies:

(1) Acceptance of two, logically incompatible theories as being equally valid. This 'dualistic' fallacy characterizes not only the 'neoclassical synthesis', which combines the Keynesian macroeconomic theory with an irreconcilable pre-Keynesian microeconomic theory, but also the prevailing theories in 'pure' trade on the one hand and the models of international money and finance on the other.

(2) Construction of models to describe the market behaviour of economic systems which offer systems which differ in their fundamental characteristics from any market economy known to have ever existed and which, for that reason, are merely constructs of the mind unrelated to any external reality. This variant of the 'solipsistic' fallacy characterizes most of the work presently being done on 'general equilibrium models'.

These two misconceptions are in addition, of course, to the 'Cartesian' fallacy which underlies economic theory more generally - that is, the belief that formal proofs alone are sufficient. This Cartesian fallacy is reflected in the mususe which economists make of mathematics (J. Blatt, pp. 166-186 in ref. 1). Rather than serving as an aid to empirical research, mathematics is used to give economics the appearance, but only the appearance, of being a science. Mathematical relationships are posited, as in the case of the utility and production functions specified above, but the unknowns remain precisely that unknowns. They cannot be given a numerical value either because the parameters are unobservable or because the functions, being insufficiently specified, cannot be solved (see the accompanying quotation from $J$. Blatt). This misuse of mathematics is justified on the grounds that all that is required is that a proposition not be illogically deduced from whatever assumptions have been made. The proposition itself, along with the assumptions from which it is deduced, need have no empirical validity.

\section{Validation}

The fact that the prevailing practice in economics runs so counter to the norms of science suggests what must be done if economics is to ever become a science. Economists must come to accept as binding on themselves the rules which govern scientific work in general. At the very least, they must recognize the need to empirically validate the core body of economic theory along with the need to replace any theoretical constructs which cannot meet that test.

It is doubtful, however, that so radical a change will occur without considerable pressure from outside the discipline. The same mechanisms which, in other fields, lead to the reinforcement of scientific norms - the system of graduate training, the appointment and tenuring of faculty, the refereeing of journal articles and the peer review of research proposals-instead act to preserve the core body of nonscientific theory in economics (A.S.E., pp. 225-235 in ref. 2; P.E. Earl, pp. 90-125 in ref. 1). It may therefore require the censure, or at least the strong protest, of the scientific community to force a change in the prevailing practice among economists. The protest would be immediate if creationists and others falsely claiming to be scientists were being similarly rewarded with grants from the National Science Foundation and with prizes from the Nobel Committee. $\square$

A.S. Eichner is at the Department of Economics, Rutgers, The State of University of New Jersey, New Jersey 08903, USA.

Why Economics is Not Yet a Science (ed. Eichner, A.S.) (Sharpe, Armonk, New York, 1983).

. Samuelson, P. Foundations of Economic Analysis, (Harvard University Press, Cambridge, Massachusetts, 1948).

Blaug, M. The Methodology of Economics 159-169 (Cambridge University Press, 1980).

4. Pasinetti, L.L. Structural Change and Economic Growth, (Cambridge University Press, 1983).

5. Eichner, A.S. Managerial and Decision Economics 4, 135-151 (1983).

6. Eichner, A.S. A Guide to Post-Keynesian Theory (Sharpe, Armonk, New York, 1979).

Eichner, A.S. \& Kregel, J.A. J. Econ. Lit. 13, 1293-1314 (1975)

8. Eichner, A.S. Towards a New Economics (Sharpe, Armonk, New York, 1985).

9. Robinson, J. Rev. econ. Stud. 21, 81-106 (1954). 